\title{
Research on the Design Process of High-speed End Mills
}

\author{
Yuanyuan $\mathrm{KANG}^{1, \mathrm{a}^{*}, \text { Yan CAO }}{ }^{1, \mathrm{~b}}$, Zhou FANG ${ }^{1, \mathrm{c}}$, Guixiang LIU ${ }^{1, \mathrm{~d}}$ \\ 1. Department of Mechanical and Electronic Engineering, Xi'an Technological University, \\ Xi'an, China \\ 1300796637@qq.com, jantonyz@163.com
}

\begin{abstract}
In order to establish the general principles and general standards for the design of high-speed cutter, this paper summarizes the research and application status of high-speed end milling cutter. It is concluded that the high-speed end milling cutter is designed only from the high-speed cutting mechanism, the cutting tool material or the stability, and so on. Therefore, it is a new trend in the design process modeling of high-speed end milling cutter to set up a design process model considering various factors.
\end{abstract}

Key words: Design process; High speed end milling cutter; Process model.

\section{Introduction}

High-speed machining (HSM) is becoming the mainstream of the cutting process, and the high-speed cutting tool is one of the key technologies to realize high speed machining. High-speed machining technology is a new common basic technology of advanced manufacturing technology, which is the development direction of cutting technology and has broad application prospects ${ }^{[1]}$. Study on high-speed cutting technology started late in China, the inevitable trend of development of high-speed cutting technology and great application prospect had not been paid attention to until late 80s when high-speed cutting technology has been applied in foreign industrial production. High-speed cutting technology can not only improve the surface quality and machining accuracy, but also improve the yield and production efficiency.

High-speed cutting tool is one of the key techniques to realize high speed machining. Recently, the modern manufacturing industry (such as automobile, mold, machine tools and other industries) has been developed rapidly; there are about 20 billion of high-speed CNC tools only in the auto industry. But only the Shanghai Tools Co., Ltd., Shaanxi Aviation Carbide Tool Company, and several can produce, the total annual production is less than 100 million yuan and the quality is still not up to the foreign advanced level. Therefore, the vast majority of high-speed cutting tools rely on imports presently; the demand of high-speed cutter localization is becoming increasingly prominent.

\section{Current Status of High-speed Milling Cutters}

Milling cutter is the main high-speed cutting tool; milling cutter industry is in a relatively rapid development period in the whole world. The manufacturers are mainly distributed among some European countries, especially industrialized countries, while the market around the world. Figure 1 is the global growth trend of high-speed milling cutter industry market from 2007 to 2013, they come from the related magazines at home and abroad, a large number of data published and provided by high-speed milling cutter industry research institutions and the survey visits to the enterprises in the industry. 


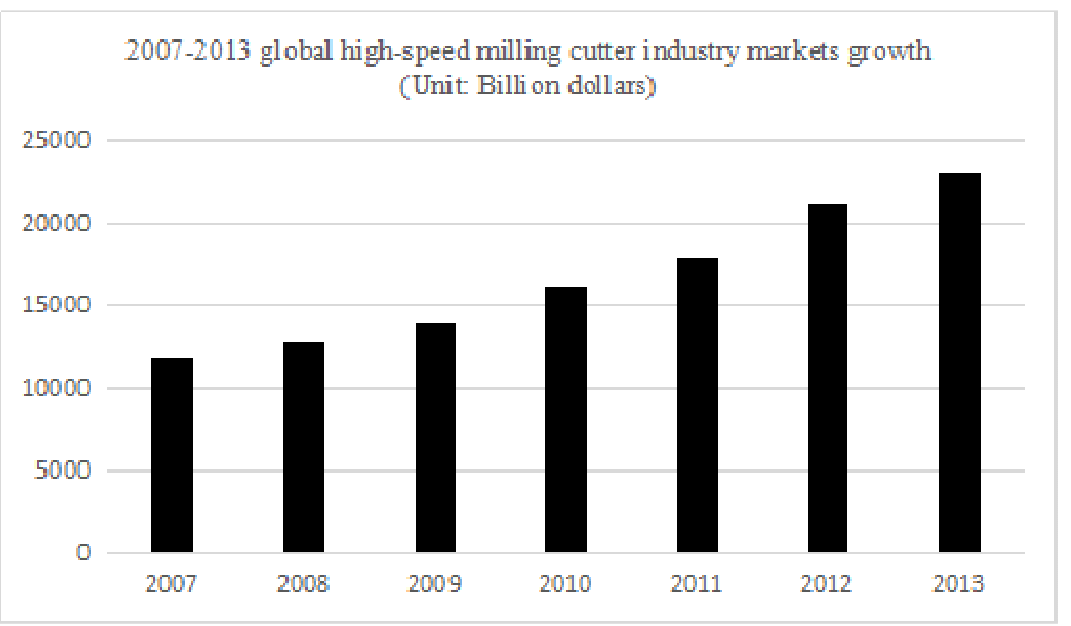

Figure 1. 2007-2013 global high-speed milling cutter industry markets growth (Unit: Billion dollars)

Currently, China's independent design and production of high-speed milling cutter is very few, the high-speed milling cutter used in China basically relies on imports. It not only improves the manufacturing cost of production, may also bring hidden dangers to our key areas, because we may be subject to others in an unusual period. Compared with foreign industrialized countries, the basic reason for the big gap is the lack of the theoretical research of high-speed tool designing process. Therefore, the design and manufacture of high-speed milling cutter is of great and far-reaching significance for high-speed cutting ${ }^{[2]}$, which is why high-speed milling tool is one of the key factors of high-speed milling technology.

\section{Research and Application of High-speed End Milling Cutter Design}

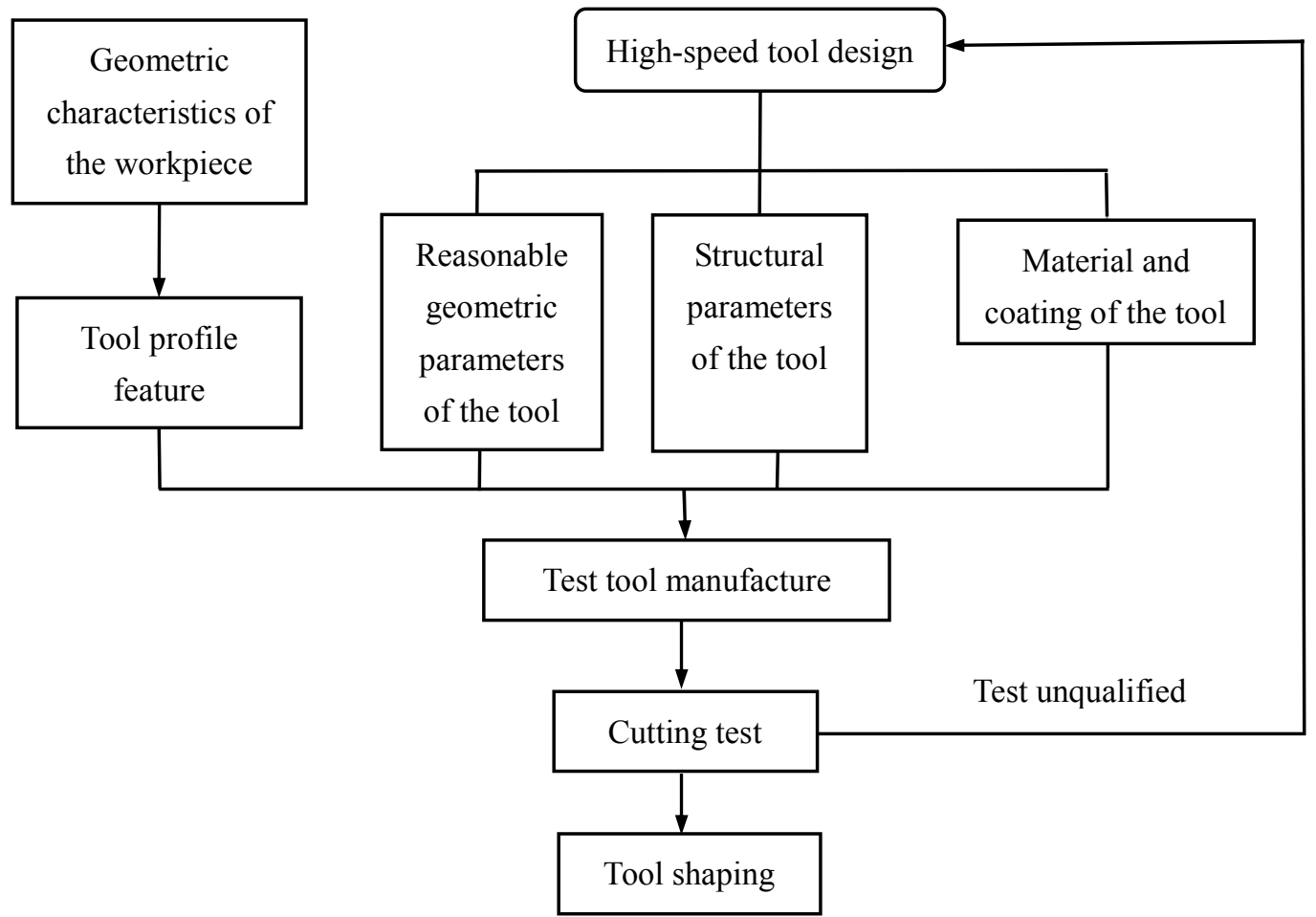

Figure 2. General design process of high-speed cutting tool

High-speed end mills are typical of high-speed milling cutter, high-speed end mills, with sufficient toughness, 
anti-wear and anti-damage performance, can withstand mechanical wear, thermal wear, and the impact load caused by the force and thermal changes. High-speed end mills can be used in a wide range of speed, especially in high-speed machining range. Through analyzing the status of the research and application of high-speed end milling cutter, it is known that the design process of high speed end milling cutter usually has the following research directions.

(1) The design based on the general principle for tool design

The design process model of high-speed end milling cutter based on general design principle is shown in Figure 2 .

Fukui Zhang ${ }^{[3]}$ mainly discussed the general design principle of design of end mills, and the reference to the different range of selecting some parameters of the cutting part of the cutting tool was put forward according to the processing of different materials in the aeronautic field (aluminum parts processing, stainless steel parts processing and hardened steel processing), which had promoted the development of high-speed tool capacity. Based on the principle of high-speed milling and combined with the performance of diamond cutting tools, Yan Song ${ }^{[4]}$ completed the overall design of the end milling cutter, including the body of the tool, the structure of blade, clamping method of blade.

(2) Design based on the principle of safety stability

The design process model of high-speed end milling cutter based on the principle of safety stability is shown in Figure 3.

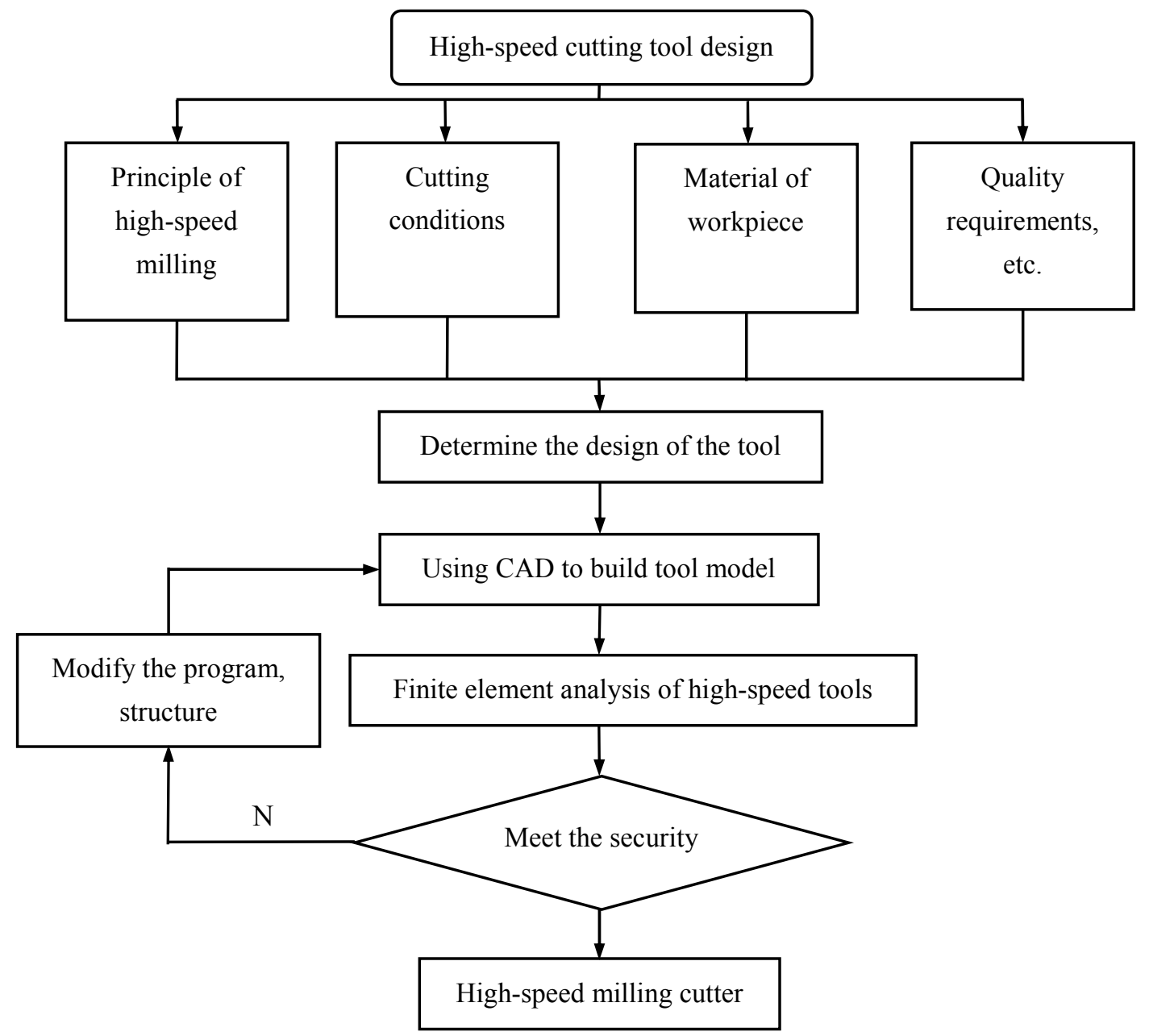

Figure 3. the designs of high-Speed Cutting cutter based on safety 
Kaiju Cheng ${ }^{[5]}$ searched for the design measures to improve the safety of tools through the study on the safety of high speed cutting tool. An unbalanced tool model was established according to the dynamic balance principle, and the dynamic balance design of high-speed milling cutter was conducted. Aimin Tang ${ }^{[6]}$ proposed a new idea of design of the structure of high-speed end milling cutter, and successfully developed a new unequal-pitch high-speed end milling cutter, which achieve the goal of improving the stability of high-speed milling. According to the requirements of dynamic balance and material of high-speed milling cutter, Xianli Fan

[7] discussed the design process of high-speed end milling cutter, so as to meet the requirements of the production, to realize the localization of high-speed end milling cutter, and to reduce the cost of cutting tools.

SGS Company launched the solid carbide end mills of Z-Carb series, which used the structure with unequal helix angel; effectively inhibit the cutting tool cutting vibration ${ }^{[8]}$. The variable chip flute type designed and developed by SAND VIK had a particularly high stability. OSG developed multifunctional cutting tool of UP-PH S series, which used the structure of four blades, and designed the unique blade flute type and the edge with anti-vibration, the tool has a good effect on reducing the cutting tool vibration, and is a tool for processing sheet.

In addition, the domestic and foreign scholars and enterprises made corresponding studies to improve the surface quality, cutting speed and tool life, and so on.

(1) Improve the surface quality of tool processing

SGS Company launched the solid carbide end mills of Z-Carb series, which used the design patent of "anti-whistle" to improve the machined surface roughness ${ }^{[8]}$. A new cutter, which has two waveforms rough edge and two spiral smooth finishing blade was launched through the innovative design of spiral blade by ISCAR company, this cutter can obtain surface quality of finish machining with the cutting parameters of rough machining, which greatly improving the cutting efficiency.

(2) Improve the cutting speed of the cutting tool

Xirang $\mathrm{Wu}^{[9]}$ had made a research introduction to the cutting tool material, the cutting edge geometry, the tool body and the connection between tool body and machine spindle. It had realized the high-speed machining of parts and increased the productivity and reduced the cost. In order to improve the production efficiency, the MillMax series high-speed and high-efficiency cutting tools is designed and developed by KENNAMETAL for the machining of aviation aluminum alloy materials (such as 7050) ${ }^{[10]}$. This series of milling cutters can carry out high-speed cutting with 25000r/min cutting speed, and can obtain excellent machining surface finish; side milling, the maximum axial cutting depth of the cutting tool is up to $25 \mathrm{~mm}$, and the cutting efficiency is very impressive ${ }^{[11]}$.

(3) Improve tool life

Japan MITSUBISHI recently launched 10 series of 324 specifications of MSTAR small diameter carbide end milling series products. This series of products is suitable for high speed and high efficiency milling, which can greatly improve the production efficiency. The series of products improve the tool life by using the new PVD coating with excellent wear resistance and oxidation resistance.

To sum up, the domestic and foreign scholars and enterprises have done a lot of research work on the mechanism of high-speed cutting, high-speed milling stability, tool life and the cutting surface quality so far, but these problems have not been systematically studied. Therefore, it is a new trend in the design process modeling of high-speed end milling cutter to set up a design process model considering various factors, so as to provide convenience for the design of the type of tool, and to improve the efficiency and quality of tool design and manufacturing. 


\section{Conclusion}

Through analyzing the status of the research and application of the design of high-speed end mill, it is concluded that the high-speed end mill is only designed from the high-speed cutting mechanism, tool life, stability or dynamic balance, but these aspects have not been systematically studied. Therefore, it is a new trend in the design process modeling of high-speed end milling cutter to set up a design process model considering various factors, so as to provide convenience for the design of the type of tool, and to improve the efficiency and quality of tool design and manufacturing.

\section{Acknowledgments}

The paper is supported by Key Problem Tackling Project of Shaanxi Scientific and Technological Office (2016GY-024), project name "the overall structure of the virtual tool design and rapid manufacturing of key technologies."

\section{References}

[1] Ai Xing. High-speed machining technology. Beijing: National Defense Industry Press, 2003.

[2] Ma Shihui. Parametric design and finite element analysis of ball end milling cutter [D]. Lanzhou: Lanzhou University of Technology, master's degree thesis, 2009.

[3] Zhang Fukui. Design and manufacture technology of carbide end milling cutter [D]. Dalian: Dalian University of Technology, 2015.

[4] Song Yan. Research on design and dynamic characteristics of high-speed diamond end mills [D]. Shenyang: Shenyang University of Technology, 2009.

[5] Cheng Kaiju. Design of high-speed face milling cutter and development of its system [D]. Harbin: Harbin University of Science and Technology, 2005.

[6] Tang Aimin. A new type of high speed end milling cutter based on cutting stability [D]. Hunan: Hunan University, 2012.

[7] Fan Xianli. Design of high speed cutting end milling cutter [C]// China Aviation Society 2007 material processing engineering academic seminar. 2007.

[8] Salmon R C S L. N-ALKYNYL-2-HETEROARYLOXYALKYLAMIDES FOR USE AS FUNGICIDES: CA, EP $1633730[\mathrm{P}] .2010$.

[9] Wu Xirang. Design of high-speed cutting tool [J]. Automotive technology and materials, 1993 (12).

[10] Zhang. Development of Mitsubishi MAX series machining aviation aluminum alloy milling cutter [J]. 2006 (5): 23-23.

[11] Shao Zidong. The structure design and performance study of high speed global carbide end milling cutter [D]. Shandong: Shandong University, 2007. 